\title{
Society of Apothecaries Diploma in Sports Medicine
}

\author{
F. B. Gibberd, MD, FRCP \\ Member of the Court of Assistants, The Worshipful Society of Apothecaries, London, UK
}

\begin{abstract}
The Society of Apothecaries examination in Sports Medicine consists of four parts: a multiple-choice question paper; a written paper; a clinical section; and an oral section. The candidates must have experience in sports medicine and have to submit a dissertation and a case history book. The importance of an examination in sports medicine is discussed.
\end{abstract}

Keywords: Sports medicine, syllabus, examination

In 1988 the Society of Apothecaries formulated a syllabus and regulations for an examination in sports medicine and held the first examination in 1989. The Scottish colleges (The Royal Colleges of Physicians of Edinburgh, Surgeons of Edinburgh and Physicians and Surgeons of Glasgow) are also awarding a diploma in the same subject. Other bodies, such as the London Hospital Medical College have awarded diplomas on examination at the end of their own courses. Physiotherapists and podiatrists are also developing professional examinations for health care in relation to sports. The examinations of the Society of Apothecaries and the Scottish colleges are the only 'open' examinations for qualified medical practitioners in the UK. This article considers the examination of the Society of Apothecaries and its relevance to sports medicine.

\section{Regulations for the Diploma in Sports Medicine}

Candidates must be registered with the General Medical Council (GMC) and have been qualified for at least 4 years. Graduates of foreign universities who are not registered with the GMC may enter if approved by the Court of Examiners.

All candidates must have: attended a full-time course in sports medicine for at least 20 weeks; attended an equivalent part-time course; attended shorter courses but practised sports medicine for at least 2 years; practised sports medicine for 4 years; or have a degree primarily concerned with sports medicine.

Address for correspondence: Dr F. B. Gibberd, Westminster Hospital, London SW1P 2AP, UK

(C) 1992 Butterworth-Heinemann Ltd 0306-3674/92/030180-5

\section{Syllabus}

The syllabus produced by the Society of Apothecaries is a guideline to candidates, but all aspects of sports medicine and illness in relation to sport may be examined. The syllabus considers ethical and social aspects, anatomy, exercise physiology and biochemistry, sports training, nutrition, psychology, environment, acclimatization, special groups in sport (for example women, children, disabled and the elderly), sports injuries, medical responsibilities, pharmacology and drug abuse, sports equipment and sport as therapy.

\section{Examination}

The examination consists of four parts: a multiplechoice question paper; a written paper; a clinical section; and an oral section. In addition, when candidates apply to sit the examination they must submit a dissertation on a subject related to sports medicine. The title must be approved and candidates are advised to write $3000-5000$ words. At the same time candidates must also submit a case-history book containing at least six case histories.

\section{The multiple choice paper}

This consists of 30 questions, with five parts in each, in the form

In condition A the following are true:

(1) The patient will be tender over $B$

(2) It is more common in tall than short people

(3) An X-ray of the area involved is usually normal

(4) It can lead to complication C

(5) It responds to treatment $D$

The candidate may answer 'true', 'false' or 'do not know'. Each part is marked separately, therefore there are 150 questions. A correct answer scores 1, the wrong answer scores -1 and 'do not know' scores nothing. Hence the total possible score is between +150 and -150 . In one of the recent Society of Apothecaries' examinations there was little difference in the number of correct answers given by each of the candidates, but a considerable difference in the number of wrong answers. There was a strong correlation between the number of wrong answers and how badly the candidate did: this meant that the best candidates were those who got the least wrong 
answers rather than those who got the most right answers. Hence the judgment when to use the 'do not know' alternative is important and candidates would be well advised to gain some experience in answering multiple choice questions. The correlation between the marks and the overall result of the examination was good. An observer (not an examiner) at a recent examination noted that those who did the worst, by answering wrongly most often, were those who dithered and had difficulty in answering questions clearly and precisely in the clinical and oral examinations.

\section{Written examination}

The written examination lasts $1 \mathrm{~h} 30 \mathrm{~min}$. The paper consists of six questions, all of which must be answered. In one recent examination candidates who did well were those who answered the question asked: it was remarkable how many candidates gave unsolicited information, limiting the amount of time to display their knowledge. The length of the answer did not correlate well with the mark although short answers lacking significant content scored poorly.

\section{The clinical section}

Each candidate sees two or more patients in $30 \mathrm{~min}$. The candidates are given an opportunity to examine the patient and, where appropriate, to take a brief history. The majority of the patients have sports injuries. The candidates are observed while they perform their examination so that the candidate's clinical expertise is easily assessed. The candidate then discusses his or her findings and possible management with the examiner.

\section{Oral section}

A viva of $15 \mathrm{~min}$ entails a discussion of at least two and usually three or more topics with a pair of examiners.

\section{Discussion}

The standing of a speciality such as sports medicine depends on the quality of the medicine practised. An examination can enhance a speciality by setting standards of knowledge, specifying recognized training programmes and requiring practical experience. An examination will bring together established practitioners in a speciality so that they can lay down a consensus on what is important in an adequate training programme. It will help lay people to decide whether someone has attained a reasonable standard. The examination fulfils the need to identify appropriately qualified practitioners for insurance purposes as well as for patient care.

An examination does, however, have disadvantages in that it tends to fix training programmes. Once a syllabus is produced it is not easily changed and courses would be constructed so that passing the examination would be used as a guide to the standards of the course.
Is an examination in sports medicine needed? There is a demand from both the practitioners and clients. Because sports medicine covers many aspects of medicine, such as musculoskeletal medicine, orthopaedics, physiotherapy and medical ethics, it is impossible to reach a position of expertise and overall knowledge of sports medicine by any other recognized medical training programme. To reach expertise in sports medicine a practitioner must be conversant with a wide range of problems connected with the discipline and must be aware of current views on management of injuries and illnesses.

An examination with a specified syllabus and which insists on certain experience or training helps develop a core group of people with sound basic knowledge and expertise in sports medicine who can be called upon by sportsmen and women and lay groups for medical advice.

Although institutes of sports medicine have developed, there was no national examination until the Society of Apothecaries instituted its diploma in 1988. This is not surprising for two reasons: first, setting up an examination requires an organization experienced in examining. The Society of Apothecaries has this experience. Second, the present specialists in sports medicine have reached their expertise in various ways. There has been no common path but a syllabus for an examination requires a consensus. Several aspects need to be considered:

Should the examination be for medically qualified practitioners alone? Most physiotherapists know a lot more about physical treatment and physiotherapy than do doctors. A separate examination for physiotherapists has been devised. Podiatrists are also developing a certificate in Sports Podiatry.

Is a single level of examination in sports medicine reasonable? An examination should be of such a standard that it is accepted by all as a sign of having reached a high level of training.

Training for surgery, pathology or anaesthetics is long and arduous, entailing an abandonment of other aspects of medicine so that only the speciality is practised for many years. Sports medicine has not yet reached the level of specialism to encourage many doctors to make a full-time commitment, although it is a subspeciality within fields such as orthopaedics, accident and emergency, physiology, musculoskeletal diseases etc. Therefore the examination must not exclude other specialities. However, in the future two levels of examination may become necessary: a higher level which would be taken by those expecting to spend the majority of their time in sports medicine, and a lower level for those practising it part time. This is not too dissimilar to opthalmology (DO and Fellowship), anaesthesia (DA and Fellowship) occupational medicine (Associate and Member of the Faculty of Occupational Medicine, The Royal College of Physicians).

By setting a syllabus a concept of the speciality of sports medicine is more easily developed and confers a greater professional status. The first word in the syllabus is 'ethical' stressing the importance of the highest standards. A syllabus needs to cover anatomy, physiology and biochemistry as they apply to exercise in general and special sports in particular. 
Environmental factors and the problems of particular groups such as women, children, the elderly and the disabled need to be understood. The ethics of how much a doctor should make it possible for a competitor to continue in an important sporting event with short-term symptomatic treatment without possible long-term disadvantages needs to be considered in spite of the competitor, the trainer or the manager wishing to bias the advice. Good knowledge and experience of sports injuries makes it possible for the doctor to reach a more informed judgment. Clinical pharmacology with knowledge of the use and abuse of drugs is also becoming more important. The Society of Apothecaries, by setting out a syllabus, has helped to define the speciality of

\section{The Diploma in Sports Medicine of The Society of Apothecaries of London}

In 1989 the Court of the Society of Apothecaries of London instituted an examination and continue to award a diploma in sports medicine which is open to registered medical practitioners who have worked in the field of sports medicine or have had other definite experience and attended a recognized course of instruction. The first examination was held in June 1989.

The training and examination is aimed at those practitioners involved in the management and treatment of injuries and other medical problems arising from sport to a degree unusual in normal medical practice. The more obvious examples are medical officers engaged by or attached to clubs such as athletics, boxing, football, hockey, swimming, etc.

The Society is a Craft Guild founded by a Royal Charter granted by King James I in 1617 and is now one of the three non-university licensing boards in the

\section{Regulations for the admission to the examination for the Diploma in Sports Medicine of The Society of Apothecaries (DSMSA)}

1 Candidates must be registered with the General Medical Council in the United Kingdom and have possessed a qualification for at least four years to practise medicine, surgery and obstetrics and gynaecology. Graduates in medicine, surgery and obstetrics and gynaecology of the British Commonwealth, countries in the European Economic Community or foreign universities, who are not registered with the GMC to practise in the United Kingdom, may be admitted to the examination by the approval of the Court of Examiners if they have complied with all other requirements of the Regulations.

C) 1992 Butterworth-Heinemann Ltd 0306-3674/92/030182-02 sports medicine and give its practitioners a framework on which to assess their breadth of knowledge and experience.

However, a syllabus alone will never be enough, and more practical experience is required. The Society of Apothecaries lay down that candidates must produce evidence of practice in sports medicine, a dissertation and a case-history book. These stipulations ensure that anyone entering for the examination has a good background in the subject. If the candidate has acquired the basic knowledge to cover the syllabus and possesses good clinical skills, then the examination should be passed without difficulty.

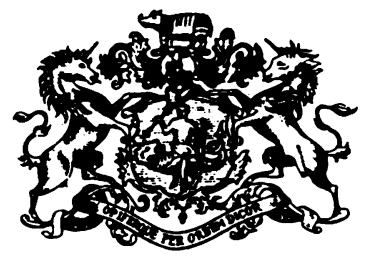

United Kingdom recognized by the General Medical Council. During its long history, the Society has instituted other examinations including the first postgraduate diploma in midwifery, the first in industrial health and currently awards diplomas in medical jurisprudence, genito-urinary medicine and the history and philosophy of medicine.

Candidates for the new diploma will have to satisfy the Court of Examiners as to their suitability to enter. Courses to be recognized are currently being conducted by:

The London Hospital - full time

The London Sports Medicine Institute-part time British Association of Sport and Medicine-part time.

The regulations and syllabus for the examination may be obtained from The Registrar, Society of Apothecaries, Blackfriars Lane, London EC4V 6EJ.

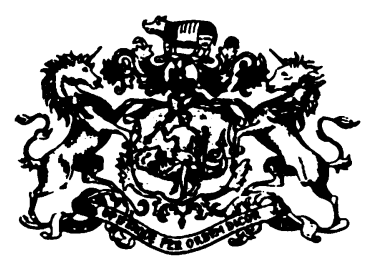

2 Candidates must produce satisfactory evidence that after qualification they have:

(a) Attended a full-time course for at least 20 weeks in sports medicine (Appendix I) recognized by the Court of Examiners and gained experience in sports medicine

or

(b) Attended a recognized equivalent part-time course 